\title{
Befristeter Vertrag und schwanger - was ändert sich?
}

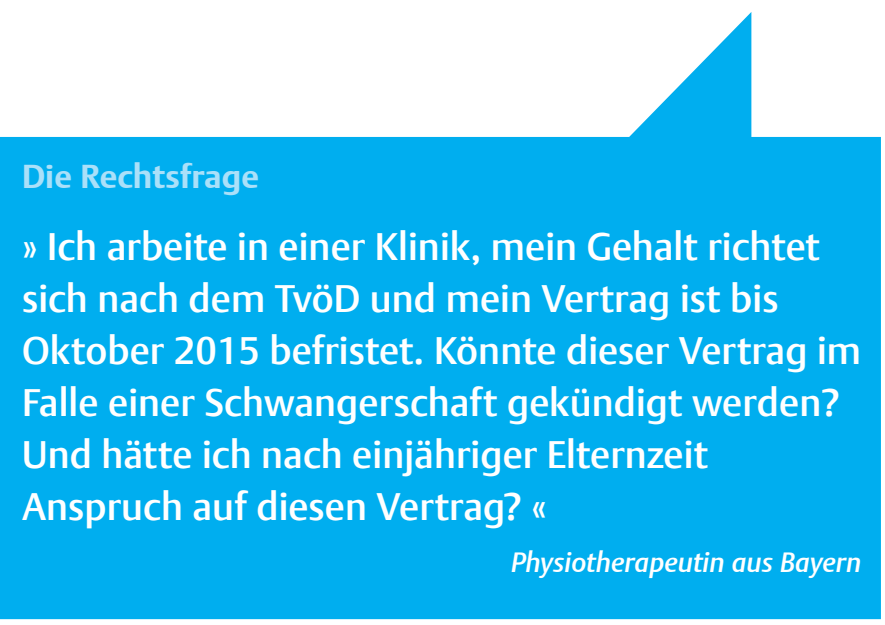

\section{Die Antwort unseres Experten}

Ein befristeter Arbeitsvertrag unterscheidet sich hinsichtlich der Rechte und Pflichten von Arbeitgeber und Arbeitnehmerin während der Schwangerschaft und Elternzeit nicht von einem unbefristeten Vertrag. In beiden Fällen gelten ein Beschäftigungsverbot nach dem Mutterschutzgesetz und die Möglichkeit auf Elternzeit. Da das Ende des Arbeitsverhältnisses beim befristeten Arbeitsvertrag bereits feststeht, kann es auch während der Schwangerschaft bzw. Elternzeit enden. Eine Kündigung, zu der die nach dem Mutterschutzgesetz zuständige Stelle ihre Zustimmung erteilen müsste, ist nicht erforderlich. Diese zuständige Behörde ist von Bundesland zu Bundesland verschieden. Interessierte finden hier nähere Infos: www.bmfsfj.de > in Suchmaske eingeben „Aufsichtsbehörden Mutterschutz/Kündigungsschutz“.

Kündigen kann ein Arbeitgeber den Arbeitsvertrag während der Schwangerschaft und Elternzeit nur unter sehr engen Voraussetzungen. Zunächst muss ein befristetes Arbeitsverhältnis laut Vertrag über- haupt kündbar sein. Der Tarifvertrag für den öffentlichen Dienst (TVöD) enthält eine solche Regelung. Zudem muss der Arbeitgeber vor Ausspruch der Kündigung die Zustimmung der zuständigen Behörde einholen. Diese darf nur in besonderen Fällen erteilt werden und darf nicht mit der Schwangerschaft bzw. Entbindung zusammenhängen. Es muss sich um Fälle handeln, in denen ein Aufrechterhalten des Arbeitsverhältnisses für den Arbeitgeber unerträglich wäre, zum Beispiel bei schweren und wiederholten Pflichtverletzungen oder einem dauerhaft stillgelegten Betrieb.

Will der Arbeitgeber während der Elternzeit kündigen oder nachdem der Antrag auf Elternzeit gestellt wurde, muss er ebenfalls vorher die Zustimmung der zuständigen Behörde einholen. Die besonderen Fälle, in denen die Zustimmung erteilt wird, finden Sie aufgelistet unter www.verwaltungsvorschriften-im-internet.de > ,Verwaltungsvorschriften“ > „Bundesministerium für Familie, Senioren, Frauen und Jugend“ >
„Allgemeine Verwaltungsvorschrift zum Kündigungsschutz bei Elternzeit“.

Im Ergebnis kann Ihr Arbeitsvertrag während der Schwangerschaft nur bei Vorliegen eines besonderen Falles gekündigt werden. Wenn das Arbeitsverhältnis nach dem Teilzeit- und Befristungsgesetz wirksam befristet wurde und während des Mutterschutzes bzw. der Elternzeit aufgrund des Fristablaufs endet, besteht grundsätzlich kein Anspruch auf einen neuen befristeten Vertrag. Karsten Bossow

\section{$\Rightarrow$ Wirft auch Ihr Berufsalltag rechtliche Fragen auf? Dann schreiben Sie an Simone.Gritsch@thieme.de.}

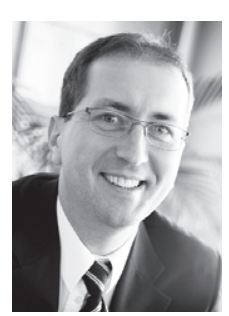

Karsten Bossow ist seit 1999 Rechtsanwalt mit den Tätigkeitsschwerpunkten Arbeits-, Medizin- und Sozialrecht. Seit 2003 ist er Fachanwalt für Medizinrecht. 